\title{
An ethical consideration of the adapted physical activity practice field
}

\author{
Ga-ram Jo* \\ Korea Nazarene University
}

\begin{abstract}
In the field of Adapted Physical Activity, there is a dearth of research that has attempted to critically explore ethical issues arising in the field of practice. The reason why ethical considerations are needed in the field of practice is that adapted physical activity instructors can negatively affect other people's lives, such as students with disability, regardless of their intentions. [Purpose] Therefore, the purpose of this study is to apply ethical theories on ethical issues that may appear in the adapted physical activity practice field and consider their implications. [Methods] Through ethics theory, researcher attempted to critically examine what is right, wrong, or good or bad in the field of adapted physical activity practice. [Results] As a result of the research, ethical theories were considered and the contributions and limitations that each theory could offer to adapted physical activity practice were discussed.
\end{abstract}

Key words: Ethics, Adapted Physical Activity Practice, Utilitarianism, Principlism, Virtue ethics, Ethics of caring

\section{서 론}

최근 언론매체를 통해 장애인 체육계의 윤리문제가 보 도되고 있다. 사설 발달 재활 센터에서 근무했던 특수체 육 지도자가 체육수업 중 장애아동의 머리를 가격하여 징 역 6개월의 실형을 선고받기도 하였으며(JoongAng Ilbo, 2016. 8. 22), 유치원에서 활동수업을 하던 교사가 장애아동을 의자에 묶고 수업을 진행하여 큰 논란이 되기 도 하였다(Yonhap News Agency, 2017. 5. 31). 이뿐 아니라, 서울의 한 대안학교에서 체육 교사가 발달 장애 아동을 림보 막대를 사용하여 폭행을 가해 피해 아동이 급성 뇌진탕 및 외상 후 스트레스 증후군 진단을 받기도

논문 투고일 : 2020. 03. 10.

논문 수정일 : 2020. 05. 06.

게재 확정일 : 2020. 05. 11.

* 교신저자 : 조가람(iverson725@hanmail.net).

* 이 논문은 2019년 대한민국 교육부와 한국연구재단의 시간강 사지원사업의 지원을 받아 수행된 연구임(2019S1A5B5A07 089524).
하였다(Sports Chosun, 2014. 9. 13). 2012년 시행된 장애인체육 (성) 폭력 실태조사에 따르면 합숙, 훈련, 시 합 등의 운동현장에서 운동지도자 $3.3 \%$ 와 특수학교 교 사 $10 \%$ 가 구타 경험이 있다고 응답한 바 있다.

장애인 체육 분야에도 윤리적 문제들이 빈번하게 야기 되고 있지만, 아직 스포츠 윤리에 대한 교육은 제대로 이 루어지지 못하고 있다(Lee, 2012). 문제는 스포츠 윤리 교육을 어떻게 해야 할지 그 방법과 내용에 대한 합의가 이루어지지 않았다는 점이다. 즉, 장애인체육 분야에서 윤리가 무엇을 다루는 것이고, 어떻게 교육할 수 있는가 에 대한 논의가 선행되지 않고 있다는 것이다. 이로 인해, 특수체육지도자는 현장에서 개인의 신념과 의지에 따라 윤리적 판단을 내리고 있으며, 특수체육지도자가 스포츠 윤리 관련 전문 정보를 얻을 수 있는 소스도 턱없이 부족 한 실정이다(Lee, 2012; Jo, 2018).

$\operatorname{Reid(2000)ㄴㅡㄴ~ㅇㅠㄴㄹㅣ~ㄱㅘㄴㄹㅕㄴ~ㅇㅕㄴㄱㅜㄱㅏ~ㅂㅜㅈㅗㄱㅎㅏㄴ~ㅌㅡㄱㅅㅜㅊㅔ~ㅇㅠㄱㅎㅏㄱㄱㅖ~}$ 의 문제를 지적하고, 특수체육이 실증적이기보다는 사회 적이고 이념적 성향이 강한 학문임을 강조하면서 특수체 
육실천 영역에서 윤리 관련 연구의 필요성을 강조하였다. 같은 관점에서 Depauw(2009) 또한, 특수체육계에 전문 가적 실천 상황에서 일어날 수 있는 윤리적 딜레마를 이 해하기 위한 전문가 윤리의 중요성에 관한 관심을 촉구한 바 있다. 과거부터 지속해서 전문가적 실천의 영역으로서 특수체육실천에 관한 윤리적 관점에서의 연구 필요성이 제기되어 왔지만, 국내 특수체육학계에서 진행된 관련 연 구는 매우 부족한 실정이다.

현재까지 국내 학술지에 게재된 국내 특수체육지도자 의 윤리문제와 관련한 연구는 단 네 편에 불과하다(Kim, Lee, 2012; Lee, 2012; Back, Park, 2016; Jo, Kang, 2019). 해당 연구들은 단순 설문조사를 통해 특수체육 전공자 또는 지도자의 윤리적 민감성에 대한 특성을 분석 했거나, 지도현장의 맥락에서 특수체육지도자가 겪을 수 있는 윤리적 갈등경험의 양상을 제시하고 있을 뿐 장애 및 윤리이론을 고찰하며 전문가적 실천영역으로서 특수 체육의 본질에 관해서는 윤리학적 분석을 시도하지는 못 하였다는 제한이 있다. 윤리이론을 토대로 특수체 육지도 자의 실천영역에 관해 고찰해보는 일은 기존 연구와 달리 예비특수체육지도자를 위한 윤리교육에 관한 시사점을 제시함과 동시에 윤리교육의 기초자료로 활용될 수 있다 는 데 중요한 의의가 있다.

윤리적 판단과정은 특수체육지도자에게 요구되는 가 장 중요한 자질 중 하나다. 윤리적 판단은 장애인에게 체 육을 지도하는 모든 과정에 수반되며, 장애인과의 관계 속에서 지도자는 무엇을 행동할 수 있는지, 무엇을 생각 할 수 있는지, 장애인의 요구에 어떻게 반응할 수 있는지 를 결정하는 매우 중요한 과정이라 할 수 있다(Cote \& Levine, 2002). 윤리적 판단은 윤리이론을 통해 정당화 되며 윤리이론은 윤리적 문제가 무엇인지를 규명하고, 해 당 윤리문제에 대한 우리의 관점을 윤리적으로 정당화하 는 데 활용된다(Ben-nett, 2010). 이러한 맥락에서 Beauchamp와 Childress(2001)는 '윤리적 실천'을 실제 지도현장에서 발생하는 윤리적 문제를 윤리학에 기초한 이론을 토대로 분석하고 확인하는 과정에 기초한 실천으 로 정의하였다.

체육학 영역에서도 윤리이론에 기초한 윤리실천에 관 한 다수의 연구가 이루어져 왔다. $\operatorname{Kim}(2015)$ 은 도핑의 비윤리적이라는 정당성을 공리주의와 의무주의로부터
확보하였으며 $\mathrm{Kim}$ and $\mathrm{Oh}(2008)$ 은 스포츠 이벤트에 대한 공리주의적 접근 방식에 대한 한계를 지적하였다. 그리고 Park(2016)은 칸트의 정언명령을 이론적 토대로 승부 조작이 왜 윤리적으로 문제가 되는지를 탐구하였다. 이처럼 윤리이론은 특정 상황 또는 행동에 대한 윤리적 정당성을 확보하는 주요 근거로 활용되기에 특수체육지 도자가 일상적으로 마주하는 윤리적 문제의 성격을 진단 하고 이해하는 데 시사점을 제공해 줄 수 있다(Goodwin \& Brenda, 2012).

그러므로 특수체육지도자의 윤리적 실천을 위해 전문 가적 실천영역으로서 특수체육을 윤리학적 이론으로 분 석해보는 것은 매우 의미 있는 일이며 이러한 분석은 윤 리이론을 고찰하는 일로부터 시작하는 것이 바람직할 것 이다(Goodwin \& Brenda, 2012). 장애와 윤리의 관계 를 탐구하는 연구들은 주로 '안락사'와 '불임' 또는 '유전자 스크린'과 같은 거대담론을 중심으로 이루어졌기 때문에 장애인들이 일상에서 직면하고 있는 윤리적 문제들은 탐 구대상에서 도외시 되어왔다(Shakespeare, 2006; Hanford, 1993). 특수체육실천의 영역 또한 거대담론에 묻혀 소외되어왔던 장애인 윤리에 관한 논의 영역 중 하 나로 볼 수 있다. 이에 본 연구에서는 윤리적 사고와 판단 의 토대가 되는 주요한 윤리이론과 장애 윤리를 바탕으로 전문가적 실천의 영역으로서 특수체육 분야에 관한 시사 점을 제언하고자 한다.

\section{윤리이론 고찰}

\section{공리주의}

휠체어 농구 시합이 진행 중이다. 경기 종료를 앞둔 시 점 $\mathrm{A}$ 팀은 $\mathrm{B}$ 팀에 5점 차로 뒤지고 있었다. 이때 $\mathrm{A}$ 팀 감독 이 작전요청을 한다. $\mathrm{A}$ 팀 감독은 포인트 가드에게 $\mathrm{B}$ 팀의 에이스인 센터가 더는 뛸 수 없게 반칙을 하라고 지시한 다. 작전 지시를 받은 선수는 감독의 지시를 실행에 옮겼 고, $\mathrm{B}$ 팀의 선수가 부상으로 경기에 뛸 수 없게 되었다. 결 국, 경기의 분위기는 반전되어 $\mathrm{A}$ 팀이 승리하게 되었다. 이때, $\mathrm{A}$ 팀 감독의 지시는 윤리적으로 정당한 것인가? 결 과적으로 $\mathrm{A}$ 팀을 승리하게 했으니 $\mathrm{A}$ 팀 입장에서는 윤리 
적으로 정당하다고 볼 수 있지 않을까? 공리주의 윤리학 은 A팀 감독의 행위에 대한 윤리적 정당화 작업에 이론적 토대를 제시한다.

사람은 보편적으로 행복을 추구한다. 사람에게는 행복 과 불행을 선택할 수 있는 권리가 있지만, 일부러 불행을 선택하는 사람은 찾아보기 어렵다. 세상 사람들의 이와 같은 자연적인 삶의 모습을 바탕으로 나오게 된 윤리 학 설이 쾌락주의다. 쾌락주의에 의하면 어떤 행위가 쾌락을 가져온다면 그 행위는 옳은 행동이며, 고통을 가져온다면 나쁜 행동이다. 공리주의는 벤담(J.Bentham, 1748 1832)과 그의 후계자 밀(J.S.Mill, 1806 1873) 이 영국의 경험주의를 바탕으로 도덕의 원리를 쾌락에서 찾는 쾌락주의를 근대사회의 도덕적 원리로 정립한 윤리 이다. 이 때문에 쾌락주의와 마찬가지로 공리주의에서도 행위가 행복과 쾌락을 산출하고 불행과 고통을 제거하거 나 방지한다면 그 행위는 옳다고 본다.

공리주의는 다음의 세 가지 전제를 바탕으로 한다 (Park, 2014). 첫째, 행위의 옳고 그름은 오직 행위에 의 한 결과에 의해서만 판단할 수 있다. 공리주의는 결과론 적 윤리체계이기 때문에 행위의 옳고 그름은 결과의 좋음 과 나쁨에 달렸다. 이때, 행위의 과정에 대한 윤리적 문제 는 논외 사항이 된다. 공리주의 창시자인 벤담 (J.Bentham)은 다음과 같이 말하며 공리주의에서 결과 주의 원리를 재차 강조하였다.

동기가 선 또는 악인 것은 오로지 그 결과에 따른 것이다. 즉, 그것은 쾌락을 산출하거나 고통을 피하는 경향 때문에 선이며, 고통을 산출하거나 쾌락을 피하는 경향 때문에 악이 다(Bentham, 1789).

둘째, 결과를 평가하는데 고려되는 유일한 요인은 행 위 때문에 생겨날 행복과 불행의 양이다. 이는 유용성 또 는 공리의 원리와 관련한 공리주의의 전제로 만일 어떤 행위가 유용하다면 그 행위는 옳다고 보는 것이다. 흔히 행복주의라고 불리는 규칙 공리주의의 주요특성이 되는 두 번째 전제는 밀에 의해 더욱 강조되었다. 밀은 '행복은 바랄만한 것이고, 더욱이 목적으로서 바랄 가치가 있는 유일한 것이며, 다른 모든 것들은 그 목적을 위한 수단으 로 서만 바랄 가치가 있다.'라고 주장하며 유용성이 방향 성 없는 단순한 감각적 쾌락을 의미하는 것이 아니라 궁
극적으로 추구해야 하는 선과 맞닿아 있음을 강조하였다.

셋째, 행복과 불행의 양을 계산할 때 어떤 사람의 행복 도 다른 사람의 행복보다 더 중요한 것으로 계산해서는 안 된다. 즉 공평성의 원리를 기반으로 한 사람의 쾌락이 다른 사람의 쾌락과 동등하게 계산되어야 한다는 것이다. 이는 윤리적 관점이 이기적이거나 자기중심적 위치를 초 월해야 한다는 보편주의 정신 또는 인간 평등 정신을 나 타낸다. 여기서 벤담은 공리의 원리를 도출하게 된다. 즉, 사회는 개인의 집합체이므로 개개인의 행복은 사회 전체 의 행복과 연결되며, 더 많은 사람이 행복을 누리게 되는 것은 그만큼 더 좋은 일이라고 보는 '최대 다수의 최대 행 복의 원리'가 바로 그것이다. 이 원리는 개인의 행복은 사 회 전체의 행복을 전제로 한 것이기에 개인보다 사회 전 체의 행복이 중시되어야 한다는 것을 뜻한다.

에피쿠로스학파가 사라진 후 서양 사회에서는 중세기 독교의 영향으로 쾌락주의 큰 관심을 받지 못했다. 그러 나 근대 시민사회가 형성될 무렵 영국 철학자들이 쾌락주 의가 사회적으로 이바지할 수 있는 측면이 있음을 발견하 게 되면서 다시 쾌락주의가 학계에 주목을 받기 시작했 다. 이후 쾌락주의에 기반을 둔 공리주의는 근대 이후 입 법을 포함한 정치, 경제, 사회 문화에 많은 영향을 끼치게 되었다(Park, 2014). 그러나 이러한 영향력에도 공리주 의는 태생적으로 다음과 같은 비판에 직면하게 되었다. 첫째, 공리주의의 결과 중심적 윤리체계는 사실판단의 대 상이 될 수는 있지만, 가치판단의 대상은 되지 못한다는 점이다. 공리주의가 경험적 사실, 즉, 더 많은 행복 경험 을 윤리적 판단의 유일한 잣대로 사용하고 있는데, 이러 한 경험적 사실은 다른 사실의 근거가 될 수는 있지만, 옳 고 그름을 따지는 도덕적 가치의 근거는 될 수 없다(Kim, 2015). 쉽게 말해, '사람은 행복을 추구한다'라는 사실이 '사람은 행복을 추구해야만 한다'는 당위 사실로 치환될 수는 없는 것이다.

둘째, 공리주의에서 가장 중요하게 생각하는 결과론적 인 공리는 정의나 개인의 권리와 같은 근본적인 도덕개념 들과는 양립할 수 없다. 이는 다음과 같은 통합체육수업 의 예를 통해 쉽게 이해될 수 있을 것이다. 통합체육수업 에서 축구를 주제로 수업이 운영된다고 가정해보자. 통합 체육수업에 자폐성 장애 학생이 한 명 있는데, 이 학생은 축구의 규칙도 잘 모르고, 관심도 없어 보인다. 자폐성 장 
애 학생 때문에 축구경기를 자유롭게 진행하지 못하는 비 장애 학생들이 선생님에게 자폐성 장애 학생을 수업에서 배제해줄 것을 요구했다. 이때, 체육지도자는 다수의 비 장애 학생들의 이익을 위해 소수의 장애 학생을 배제하는 것은 공리주의 윤리관에 비추어 타당한 결정이라 생각할 수 있을 것이다. 그러나 이러한 결정은 우리의 상식적인 도덕 감에서는 받아들이기 어려운 도덕 판단으로 귀착된 것으로 느껴진다. 이러한 불쾌감의 기저에는 윤리적 정당 화 과정에서 행복이라는 결과를 위해 도덕을 단지 수단적 위치로 끌어 내린 것에 대한 도덕적 불편함이 자리 잡고 있기 때문이다.

공리주의가 특수체육실천영역에서 윤리이론으로 적용 되는데 위와 같은 한계가 존재하더라도 다음과 같은 의의 는 부정할 수 없다. 첫째, 공리주의는 문제 사태가 발생했 을 때 비교적 쉽고 빠르게 도덕적 판단을 내릴 수 있다. 앞서 언급했듯이 공리주의는 행위자의 동기나 의도보다 는 그 행위의 결과가 더 많은 사람의 만족과 행복을 가져 올 수 있는 행위가 도덕적으로 선하고 올바르다고 설명하 기 때문에 특수체육지도자들이 실천영역에서 더욱 쉽게 도덕적 의사결정을 하는 데 활용할 수 있는 윤리이론이 될 수 있을 것이다. 특수체육실천의 실제 영역은 비교적 빠른 도덕 판단을 요구하는 상황이 많으므로 이러한 공리 주의에 의한 행위판단은 장점이 될 수 있다.

둘째, 공리주의는 사회 운영의 원리로 등장한 이론 (Park, 2014)이기 때문에 입법이나 공동정책의 내용을 결정할 때에 매우 합리적이다. 이러한 공리주의의 특성은 예비특수체육지도자 양성 단계의 지도자들이 실습현장 에서 함께 토의와 합의를 통해 게임수업의 규칙을 수정하 거나 변형할 때 유용하게 활용될 수 있다. 입법의 측면에 서 게임이나 스포츠에서의 규칙은 법과 도덕성 판단의 기 준으로 작용할 수 있다는 점 $(\mathrm{Oh}, \mathrm{Kim}, 2015 ; \mathrm{Seo}$, Hwang, 2014)을 고려하면 공리의 도출을 통한 규칙의 제정과 변형은 예비특수체육지도자의 도덕성 발달에 긍 정적으로 이바지할 가능성이 높다.

\section{의무주의}

공리주의가 최대 다수의 행복을 최대화하는 것을 목적 으로 정하고 이에 준하여 행위의 결과에 대한 옳고 그름
을 평가하는 목적론적 윤리였다면 의무주의 윤리는 행위 의 결과보다는 행위의 동기가 보편적으로 옳은지 그른지 를 판단하는 윤리체계다. 의무주의는 윤리에 대해 공리주 의와 정 반대되는 견해를 전개했던 철학자 임마누엘 칸트 (1724 1804)의 저술에 기초를 두고 있다. 그는 윤리 규범은 행복을 저울질하여 더 많은 행복을 추구하기 위한 가변적 수단이 아니라 상황에 상관없이 보편적이어야 한 다고 주장하였다. 그는 인간이 이러한 보편적 지침을 '순 수이성'과 '선의지'를 통해 발견할 수 있다고 보았다.

칸트는 그의 저서 '실천이성비판'에서 “도덕법칙은 순 수이성의 사실로서 주어져 있고, 우리는 그것을 선험적으 로 인식하며 절대적으로 확신한다.”라고 하며 보편적 도 덕법칙 발견의 여정을 위한 디딤돌로 '순수이성'을 제시하 였다. 순수이성이란 인간의 경험 이전에 선험적으로 존재 하는 추론 능력으로 시 공간을 초월하여 보편적이고 필연 적인 진리를 우리에게 알려줄 수 있다(Park, 2014). 즉, 칸트는 1 더하기 1 이 2 라는 보편적 진리를 시대와 공간을 초월하여 모든 이성적인 인류가 추론해낼 수 있는 것과 마찬가지로 순수이성을 통해 도덕적 진리를 발견해낼 수 있다고 보았다.

순수이성과 함께 의무주의를 구성하는 주요 개념 중 하나는 '선의지'다. 의무주의에서는 행위의 옳고 그름에 대한 윤리적 판단을 결과가 아닌 그 결과를 낳은 의지에 근거할 뿐이라고 설명한다. 어떤 조건에도 영향을 받지 않는 절대적 선으로 간주할 수 있는 선의지는 부유함, 명 예, 용기, 재능과 같은 윤리적 선들과는 차별성을 가진다. 그 이유는 오로지 선의지만이 본래성을 갖는 목적 그 자 체의 동기로 악한 목적에 이용될 수 없기 때문이다. 가령, 강인함, 지성, 용기 부유함 같은 선은 범죄에 이용될 수 있다. 반면에 선의지는 그렇지 않다. 선의지는 모든 선의 근본이 되는 선으로 선의지가 없다면 다른 선들은 모두 악에 이용될 가능성을 항상 내포하게 된다. 따라서 선의 지만이 절대적인 선의 의미를 소유할 수 있으며 이를 통 해 선의지는 인간이 모두 추구해야 할 보편성을 획득하게 된다.

칸트는 '네 의지의 준칙이 언제나 동시에 보편적 입법 의 원리가 될 수 있도록 행위하라.'라고 주장함으로써, 순 수이성과 선의지에 기반하여 발견할 수 있는 보편적 도덕 원칙으로 정언명령 (categorical imperative)이라는 격률 
(maxim, 행위의 원칙)을 제시하였다. 어떤 행위가 도덕 적으로 옳은 것이라면 그것은 당연히 모든 사람과 모든 경우에 적용될 수 있는 법칙이 되어야 한다는 것이다. 정 언명령은 조건에 따라 원칙이 변할 수 있는 가언명령과는 구별되는 도덕 명령으로 '정언'이라는 말은 '가언'과 달리 예외가 없다는 뜻이며 명령이라고 하는 것은 원칙으로부 터 도출된 규범이라는 뜻이다. 따라서, 정언명령은 '너는 무조건 이것을 행해야 한다.'와 같은 형식을 취할 수밖에 없다.

칸트는 정언명령 외에도 '사람(자기 자신이든지 다른 사람이든지)을 대할 때는 그 사람을 수단이 아닌 목적으 로 대하라.'라는 실천명령의 행위 원칙을 제시함으로써 의무주의윤리가 인간 존엄의 보편성에 기반이 되도록 하 였다. 그는 보편적 윤리 규범이 실천명령의 행위 원칙을 만족하게 하는 동시에 그의 정언명령으로부터 도출되어 야 한다고 보았다. 여기서 유의하게 살펴보아야 할 것은 정언명령과 실천명령은 서로 구별되거나 어긋나는 개념 이 아니라는 점이다. 칸트는 이 둘을 사실상 같은 개념이 라고 말한 적이 있는데, 이는 보편주의 이념이 인간 존엄 성의 이념과 같은 선상에서 이해되어야 함을 뜻한다. 즉, 모든 사람에게 동등한 보편적 원리를 적용한다는 것은 그 들을 수단이 아닌 목적으로 대우한다는 것이고 그들을 목 적으로 대우한다는 것은 곧 모든 사람에게 같은 도덕 원 리를 적용한다는 것과 같은 의미라는 것이다(Park, 2014).

칸트의 의무론은 공리주의로 인해 수단으로 전락해 버 린 윤리의 가치를 목적으로 끌어올리는 동시에 인간의 존 엄성에 절대적 가치를 부여하였다는데 의의가 있다. 그러 나 의무론을 인간의 복잡다단한 생활세계의 윤리적 문제 들에 대입해보면 그 한계가 드러나게 된다. 사회 속에서 이루어지는 인간의 행위가 매우 복잡하다는 사실을 고려 하면, 의무론은 예외를 인정하지 않고 엄격하기에 현실 세계에 적용성이 떨어져 보인다(Park, 2014). 특수체육 지도현장을 예로 들어보자. 스마트폰을 가지고 노느라 체 육수업에 집중하지 못하는 지적장애 학생이 있다. 어느 날 수업시간에 지적장애 학생이 교사에게 다가와 스마트 폰이 있느냐고 물었다. 이때 교사가 스마트폰을 가지고 있었지만, 학생의 원활한 수업참여를 위해 스마트폰이 없 다고 소위 '착한 거짓말'을 했다. 이때 해당 교사의 행위는
윤리적으로 그른 것일까? 의무론에 의하면 그른 행위이 다. 왜냐하면, 의무론은 상황 맥락과 결과에 상관없이 행 위 자체의 절대성을 강조하고 있기 때문이다. 그러나 대 다수의 특수체육 지도자들은 학생의 체육수업 참여를 위 해서 어쩔 수 없이 거짓말을 할 수밖에 없었던 특수체육 교사의 행위에 공감했을 것이다. 이렇듯, 의무론은 옳고 그름을 분별하는 최소한의 기준으로서는 매우 의미가 있 지만, 실제상황 맥락을 고려하지 않는다는 점에서 현실윤 리문제 해결에는 큰 도움을 주지 못한다.

의무주의 윤리는 특수학교체육이나 장애인 엘리트 체 육 현장에서 지도자들에게 윤리원칙 준수의 중요함을 일 깨워주는 동시에 도덕적 상대주의를 극복하여 도덕적 자 율성과 책임의식을 길러줄 수 있다는 장점이 있을 수 있 다(Lee, 2016). 그러나 '순수이성'을 바탕으로 '선의지'를 실현하기 어려워 보이는 발달 장애 학생과 선수들이 스스 로 보편화 가능한 도덕법칙을 설정할 수 있는지에 대해서 는 의문이 들게 한다. 인간 존엄의 근거를 이성에 기반을 두고 있는 의무주의 윤리는 필연적으로 이성 능력에 제한 이 있어 보이는 사람들의 존엄성을 보장하기 위한 윤리이 론으로 사용되기에는 한계가 있어 보인다.

이상의 한계가 존재하지만 의무주의는 예비특수체육 지도자에게 특수체육실천상황에서 조건이나 상황에 따 라 변하지 않는, 규칙을 꼭 지켜야 하는 의지를 길러준다 는 점에서 중요한 의의가 있다. 상황에 따라 규칙의 적용 이 달라지지 않는다는 것은 규칙 준수의 소중함과 존엄함 을 일깨워주는 동시에 도덕적 상대주의를 극복할 수 있게 해주기 때문이다. 실습과정에서 의무주의 윤리를 실천하 는 과정을 통해 예비특수체육지도자들은 도덕적 자율성 과 책임의식을 함양한 특수체 육지도자로 성장할 수 있다. 이러한 맥락에서 실습영역에서 예비특수체육지도자 들 에게 활동 및 규칙의 규범적 성격을 보다 강조할 필요가 있다. 특수체육의 실천영역이 주로 스포츠를 기반으로 하 고 있으며, 스포츠에 있어 규칙 준수의 윤리적 정상성은 의무론과 같은 규범 윤리의 범주로 접근할 때 보장될 수 있기 때문이다(Kim, Kim, 2010).

\section{원칙주의}

원칙주의는 응용윤리학의 방법론의 하나로 '중간수준의 
원칙'에 따라 윤리적 판단을 수행하는 것이라 할 수 있다. 여기서 중간수준의 원칙이란 의무론에서 주장하는 바와 같은 보편적 원칙이 아니다. 이는 유연성을 가지고 있는 원칙으로서 심층적 수준에서는 논쟁이 불가피하더라도 표층적 수준에서는 구체적 논쟁을 폭넓게 수용할 수 있는 최소한의 윤리적 실천적 지침을 말한다(Yoo, 2016). 이 런 맥락에서 원리주의를 최소전략(Minimalist)이라고 부르기도 한다.

원칙주의는 자율성 존중의 원칙(Respect of Autonomy), 악행 금지의 원칙(Nonmaleficence), 선행 의 원칙(Beneficence), 정의(Justice)의 원칙으로 구성 된다. 원칙주의의 네 가지 원리는 Beauchamp와 Childless(2001)의 '생명 의료 윤리의 네 가지 원칙'이라 는 저서를 통해 소개되었으며 1979년 책이 처음 출간된 이래로 2012년 제7판까지 개정이 이루어질 정도로 미국 뿐만 아니라 한국에서도 생명윤리학 분야의 개론서로 폭 넓게 활용되고 있다.

원칙주의를 구성하는 네 가지 원리를 구체적으로 살펴 보면 먼저 자율성 존중의 원칙은 타인의 자율성에 대한 윤리적 의무를 나타내는 것으로 거짓이나 억압으로부터 자유롭게 한 사람의 삶에 영향을 주는 문제에 대해서 선 택할 수 있는 자유를 나타낸다. 이 원칙은 다음의 네 가지 의 전제를 기본으로 한다(Burkhardt \& Nathaniel, 2013). 첫째, 자율적인 사람이 존중된다. 둘째, 자율적인 사람은 자신의 목표를 스스로 결정할 수 있어야 한다. 셋 째, 자율적인 사람은 행동계획을 결정하는 능력이 있다. 넷째, 자율적인 사람은 자신의 선택에 따라 행동할 자유 를 가진다. 자율성 존중의 원칙은 현실 상황에서 기본적 으로 동의를 표현하는 것으로 구현될 수 있다. 여기서 동 의는 충분한 정보 제공을 바탕으로 이루어지는 것으로 의 사결정 능력과 결정에 대한 자발성이 포함된다.

두 번째는 악행 금지의 원칙이다. 이 원칙은 선행과 관 련된 것으로 타인에게 피해를 주지 말아야 한다는 의무를 뜻한다. 이때 피해는 그 자체뿐 아니라 피해의 가능성이 될 수 있는 위험까지 포함한다. 일반적으로 피해라고 하 면 명예, 재산, 사생활, 자유 등의 훼손과 같은 넓은 의미 로 이해될 수 있지만, Beauchamp와 Childress는 이를 생명윤리분야에 국한하여 건강과 생존과 관련된 신체적 이고 심리적인 이익 훼손의 의미로 한정하였다.
세 번째로는 선행의 원칙이다. 선행의 원칙은 해악 금 지의 원칙과는 반대로 ' 하라'의 형태로 되어 있다. 선행 의 원칙은 행위자들로 하여금 단지 해로운 행위를 하지 않을 것만을 요구하는 것을 넘어서는 보다 적극적인 의미 를 담고 있다. 타인을 돕기 위해 적극적인 조치를 취하기 때문에 해악 금지의 원칙보다 잠재적으로 더 많은 것을 요구하는 원칙이라고 볼 수 있다.

네 번째로는 정의의 원칙이다. 분배의 정의라고 불리 기도 하는 정의의 원칙은 타인을 공정하고 공평하게 적절 히 대우하는 것과 관련한 윤리원칙이다. 불행하게도 서비 스와 물자는 제한되어 있기에 모든 사람이 원하거나 필요 로 하는 모든 것을 갖는 것은 불가능하다. 따라서, 서비스 를 제공하는 시설 관리자의 일차적 목적은 부족한 자원에 대한 공정하고 공평한 배분 방법을 제시하는 것이 된다.

이러한 원칙주의는 실제 현장에서 일하는 실천가들이 나 정책입안자들이 일상에서 마주하는 복잡한 윤리문제 들에는 적용하기 쉽지 않다는 비판을 받아왔다(Austin 2007). 비슷한 맥락에서 Clouser \& Gert(1990) 또한 원칙주의는 사람 간의 관계를 무시하고 모든 윤리적 상황 에 대해서 적용 가능한 요리책 (a recipe book)과 같이 단 순한 점검표에 지나지 않는다고 비판하기도 하였다. 그러 나 Beauchamp(1995)는 원칙주의를 신중하게 적용함에 있어서 '책임'이나 '진정성'과 같은 개인의 성품에 기반하 여 이루어지는 능숙한 판단을 필요하다고 주장하며 원칙 주의가 개인의 실천적 지식을 무시한 채 원칙만을 적용하 는 것이 아님을 강조하였다.

원칙주의가 제시하는 원칙을 특수체육실천 분야에 그 대로 적용할 수 있는가에 대해서는 비판적 검토가 필요하 다. Goodwin(2008)은 장애인의 체육참여 주요 목표로 설정되는 '기능적 독립'에 관한 윤리적 함의에 관한 연구 에서 '자율성'이라는 생명윤리의 주요 가치가 '사회적 상 호의존성'을 간과하고 있다고 비판하였다. 가족관계와 친 구 관계와 같은 모든 친밀한 관계는 본질적으로 상호의존 성에 기반을 두는 관계라고 할 수 있다. 특수체육수업 상 황에서도, 지도자와 장애 학생 장애학생과 장애 학생은 각각 독립적으로 존재하는 것이 아니라 상호 의존하며 존 재한다. 이러한 맥락에서 우리가 일반적으로 생각하고 있 는 특수체육 지도의 목표로 과연 장애인의 독립성 획득이 가능하며 매력적인 목표가 될 수 있는지, 또한 이를 특수 
체육의 목표로 바라보고 추구하는 것이 윤리적으로 올바 른 것인지 비판적으로 검토해볼 필요가 있다(Cardol, De Jong, \& Ward, 2002; Macklin, 1998).

\section{덕윤리}

인간의 행위는 '정언명령'과 '유용성의 원리'에 의해 설 명되지 않는 복잡성을 바탕으로 이루어지기 때문에 삶과 동떨어진 추상적 도덕 원리보다는 감정과 이해타산 그리 고 공동체 문화에 따라 이루어지는 경우가 훨씬 많다 (Kim, 2015). 공리주의와 의무주의 윤리가 실제 삶의 맥 락에서 인간 개인이 어떤 사람이 되어야 하는지에 대한 답은 제시하지 못한 채 '법칙 적인 윤리개념'에만 집착했 다는 비판 속에서 대안으로 등장한 것이 덕 윤리이다 (Park, 2014). 덕 윤리는 기존의 공리주의와 의무주의 윤리의 주요 논제였던 '무엇을 해야만 하는가?'가 아니라 '어떻게 살아야 하는가?'에 초점을 둠으로써 행위에 대한 '의무 판단' 보다는 행위자의 '덕성 판단'을 중시한다 (Byun, 2012). 이는 행위자체 (act-focused)에서 행위자 (agent-focused)로의 대전환을 의미한다.

덕윤리가 비교적 최근에 기존 윤리이론의 문제에 대한 대안으로 등장하기는 했지만, 덕윤리 자체의 기원은 고대 그리스까지 거슬러 올라간다. '니코마스 윤리학'을 저술 했던 아리스토텔레스에 의하면 인간 행위에 대한 옳고 그 름의 문제는 보편적 규칙이나 원칙에 근거해서 판단해야 할 것이 아니었다. 오히려 윤리적 판단의 정당성은 도덕 적 사고, 욕구, 행위의 좋은 습관과 결부된 감수성이나 세 련된 식견과 같은 개인의 덕을 통해 확보될 수 있다고 보 았다. 그는 개인이 도덕적인 덕을 갖추기 위해서는 오랜 시간 동안 절제, 용기, 너그러움 등을 습관화하여 실천함 으로써 비로소 알게 된다고 하였다(Kim, 2015). 다시 말 하면 절제, 관용, 인내, 용기 등의 덕목이 무엇인지는 실 천하기 전에는 결코 알지 못하며 실천한 후에야 그 실체 가 무엇인지 드디어 알게 되듯이 옳은 행위는 저절로 생 기는 것이 아니라 그 행위를 실천할 때 비로소 자신의 것 이 된다는 것이다. 따라서, 덕윤리에서는 '실천'을 매우 강 조할 수밖에 없다. 이러한 점은 도덕적 '덕'을 기르는데 반 드시 교육이 필수적임을 드러낸다.

덕윤리를 특수체육실천 영역에서 적용하는 데 있어 고
려해봐야 할 점은 다음과 같다. 지도현장에서 장애 학생 을 친절하게 대하는 것은 특수체육지도자의 덕성을 나타 내는 것이지만, 지도현장의 장애 학생 또한 이러한 지도 자의 덕성으로 인한 유익이 있어야 비로소 '덕스러움'이 실현된 것이라 할 수 있다. 다시 말하면, 덕윤리의 관점에 서 특수체육지도자의 선의의 도움이 장애 당사자에게는 부정적인 영향을 미치거나 지도자의 선의가 타인보다는 스스로의 만족만을 위하게 되는 경우 이러한 특수체육지 도자의 행위를 '윤리적으로 옳은 행위’로 판단할 수 있는 가에 대해서는 많은 의문이 들 수 있다는 것이다. 그러므 로 덕윤리의 관점에서 특수체육 지도의 실천영역을 깊이 있게 논의하려면 특수체육실천 영역의 주체인 특수체육 지도자와 장애 학생 또는 장애 학생 간의 관계가 올바로 정립되는 것이 중요하다(Begley, 2006; Clegg, 2000).

덕윤리와 관련한 특수체육학 내의 연구를 살펴보면 Goodwin과 Watkinson(2000)는 지체 장애아동을 대상 으로 한 체육수업에서 동료 학급 학생의 불필요한 간섭으 로 또래 장애 학생의 신체활동 참여가 제한받았으며, 적 절한 신체활동 참여기회의 박탈로 이들의 인지된 신체 유 능 감이 저하되고 있음을 발견하였다. 이러한 연구를 바 탕으로 Goodwin은 선의를 가진 학생이 하려는 행동을 통 해 나타나게 될 결과에 대한 상호 간의 합의가 고려되어 야만 특수체육상황에서 또래 간의 긍정적인 상호작용이 이루어질 수 있다고 하였다. 그러나, Goodwin은 이 모든 조건이 충족되었다 하더라도 또래 학생으로부터의 도움 을 받는 학생이 동료 학생의 도움으로 인해 스스로 독립 되어 있지 못하거나 자아존중감이 떨어지고 있다고 느낀 다면 이는 위험한 것이라고 보았다.

특수체육의 전문가적 실천영역에서 많이 활용되고 있 는 '또래 교수 방법'은 덕윤리를 통해 고찰할 때 그 사용에 대한 유익과 불이익 또는 그 사용 방식에 대한 윤리성과 비윤리성에 관한 유의미한 시사점을 고찰해볼 수 있다. Benner(1997)은 덕윤리가 제시하는 것처럼 도움을 받 는자가 아니라 도움을 주는 행위자의 성격에 집중하는 것 은 도움을 주는 자가 상호존중하는 방식으로 타인에게 도 움을 주지 못하고 자기중심적인 방법으로 일방적 기여자 의 역할에 머물 수밖에 없음을 의미한다고 하였다. 앞선 연구자들이 언급한 것처럼 특수체육지도자가 장애 학생 에 대한 자신의 역할을 일방적인 선의의 기여자로 상정하 
고 이루어지는 특수체육 실천은 오히려 장애학생을 수동 적 존재로 전락시켜 소외시키는 우(愚)를 범할 수 있다 (Jo, 2018).

특수체육실천영역에서 덕윤리가 이상의 한계를 보임 에도 교육의 관점에서 덕윤리는 다음과 같은 유익이 있다 고 할 수 있다. 첫째, 덕윤리가 습관화를 강조한다는 점에 서 특수체육실천의 영역과 밀접한 관련이 있다. 발달장애 학생의 경우 정신연령이 지체됨에 따란 추상적이거나 복 합적인 사고가 어렵고 자기중심적인 사고로 타인을 배려 하는 행위가 어려울 수 있다. 따라서 몸의 움직임을 통한 실천적인 특수체육은 도덕적 가치가 되는 습관화의 교육 에 긍정적인 영향을 미칠 수 있다(Jang, Lee, 2014).

또한, 덕윤리가 소규모 공동체 사회에 적합한 이론이 라는 점을 고려하면 덕윤리는 소규모 그룹중심으로 이루 어지는 특수체육수업상황에 유의미한 시사점을 제시할 수 있다. 소규모 그룹 수업에서 학습자인 장애 학생은 체 육활동을 통해 가치관의 공유, 갈등의 극복, 활동에 서의 배려 등 일반적으로 사회생활에서 발생할 수 있는 사람들 간의 다양한 문제를 조금이나마 경험하고 이를 해결해 볼 수 있는 연습의 기회를 제공받을 수 있다. 이는 장애학생 들이 신체활동을 통해 일상생활로의 전이가 가능한 활동 적인 생활 기술(active life skill)을 습득해볼 수 있다는 점에서 중요한 의미를 내포하고 있다(Yoo, Seo, Jang, Kim \& Kwon). 따라서 장애학생들은 체육활동을 통해 사회생활에 필요한 다양한 기술을 습득할 수 있을 것이 다. 소그룹으로 적용되는 특수체 육실천은 덕윤리를 적용 하는데 있어 적합한 환경을 제공해줄 수 있을 것이다(이 정택, 2016).

\section{돌봄의 윤리}

돌봄의 윤리는 이성과 합리성, 자유주의와 개인주의의 확대가 사람들 간의 공동체를 해체한다는 비판 속에 대두 된 윤리이론으로 돌봄, 신뢰, 관용, 존중, 책임감 등의 덕 목을 인간의 핵심적 가치로 상정한다. 돌봄의 윤리는 '여 성윤리(feminine ethic)'라고 불리기도 하는데 그 이유는 돌봄의 윤리가 모성적 사고에서 아이디어를 찾은 쵸도로 우, 길리건, 나딩스, 트론토 등에 의해 제창되고 발전되어 왔기 때문이다. 이러한 여성주의 철학자들은 그동안 결핍
되고 열등하게 취급되어온 여성의 도덕적 특성을 새롭게 조명하였다.

특수체육지도자의 전문가적 실천의 특성은 본질적으 로 관계 중심적인 것이다. 따라서, 특수체육지도자는 장 애인의 삶에 깊이 관여하며 정서적으로 그들의 행복을 지 지하고 공감해주어야 한다(Oberle \& Raffin Bouchal, 2009). 돌봄의 윤리는 관계를 중요시하는 윤리로 타인의 '성장' 또는 '자기인정'을 위한 지원에 초점을 두고 있다. 이러한 돌봄의 윤리는 관계 중심적이기 때문에 원리주의 와 같은 생명 의학 윤리의 대척점에서 주로 간호학 실천 의 주된 윤리이론으로 활용되어왔다.

돌봄의 윤리를 주창한 학자들에 의하면 돌봄에는 두 가지 조건이 있다. 첫 번째는 돌봄을 받는 사람에게 정서 적으로 몰입하며, 자신의 온전한 관심을 상대방에게 주는 것이다. 두 번째는 첫 번째 경우와는 반대로 돌봄의 행위 를 하는 데 있어 감정을 완전하게 배제한 채 이루어지는 돌봄이다. 이러한 돌봄의 윤리는 실제 경험을 통해 실제 적 판단력과 같은 '실천적 지식'을 얻을 수 있다는 점에서 덕윤리와 유사한 점이 많다. 그러나, 이러한 유사함에도 덕윤리와 돌봄의 윤리가 결정적으로 다른 것은 '관계'에 있다. 덕윤리가 행위자 개인의 성품에 관한 것이라면 돌 봄의 윤리는 타인과의 관계라는 특정 문맥 속에서 어떻게 대응할 것인가에 관한 '관계적 자질'인 것이다.

돌봄의 윤리적 관점에서 볼 때 '좋은' 또는 '윤리적인' 특수체육지도자는 지도현장에서 벌어질 수 있는 장애인 과의 다양한 관계 속에 잘 적응하고 장애인의 개인적 관 심과 필요에 깊이 반응할 수 있는 지도자이다. 더 나아가 돌봄의 윤리는 개인의 독립보다는 '돌봄'과 '상호의존'을 전문가적 실천의 궁극적 목표로 내세운다. 이러한 돌봄의 윤리적 접근에는 실천현장을 '감정'과 '이성'이 융합된 곳 으로 본다. 여기서 감정은 이성적 인식을 방해하는 '소음' 이상의 것이다. 이러한 감정은 돌봄이라는 행위 속에서 타인에 더 면밀하게 반응할 수 있게 해주는 증폭기 역할 을 한다(Benner, 1997). 따라서, 돌봄의 윤리에서 중요 한 질문은 ‘어떻게 타인과 윤리적으로 만날 수 있을까?’이 다(Noddings, 1984).

덕윤리와 비슷한 점이 많은 돌봄의 윤리는 덕윤리가 받는 비판점과 동일한 측면에서 비판을 받을 수 있다. 돌 봄의 윤리가 돌봄은 항상 옳다는 일방적인 윤리적 방향성 
을 전제로 하고 있으므로 '전문가'를 '보호자'나 '간병인' 정 도로 여기게 한다는 비판이 있다. 돌봄의 윤리에 의하면 특수체육지도자는 그저 장애 학생을 돌보는 '보모' 정도에 머물게 되는 것이다.

또한, 돌봄의 윤리가 독립적 삶과 자기 결정을 경험하 기 원하는 장애인의 옥구를 저해한다는 비판점도 존재한 다. 만약 특수체육지도자가 돌봄의 윤리적 관점에서 장애 학생을 지도한다고 한다면, 해당 지도자는 장애 학생의 자립 욕구가 분명히 존재함에도 이를 무시하게 될 공산이 크다. 돌봄의 윤리는 돌봄의 도덕적 선함이 돌봄의 행위 그 자체나 돌봄을 받는 사람의 관점에서 인식되는 돌봄의 결과와 상관없더라도 돌봄은 언제나 옳다고 전제한다. 따 라서, 특수체육 지도현장에서 돌봄의 윤리를 기반으로 전 문가적 실천을 수행하기 위해서는 윤리적 돌봄을 위해서 는 돌봄의 목적과 방법에 대한 비판적 검토 및 돌봄기술 에 대한 세심한 윤리적 고려가 뒷받침되어야 한다 (Allmark, 1995).

\section{장애 윤리: ‘전문가'로서 장애인}

장애윤리(Disability ethics)는 학제적 (interdisciplinary) 성격이 강한 응용윤리의 한 범주로 '장애인의 삶'에 관한 윤리적 딜레마를 주요 연구의 영역 으로 다룬다. 장애 윤리에 의하면 특수체육실천영역에서 의 전문가는 크게 두 가지 관점에서 이해될 수 있다. 첫 번째는 우리가 일반적으로 생각하듯이 특수체육 서비스 를 제공하는 전문가로서의 특수체육지도자이다. 국어사 전에 따르면 전문가란 '어떤 분야를 연구하거나 그 일에 종사하여 그 분야에 상당한 지식과 경험을 가진 사람'으 로 정의된다. 특수체육에 대한 충분한 지식과 경험이 있 는 자가 특수체육전문가인 것이다(Carlson, 2010). 그 러나 특수체육 분야는 전문가에게 지나치게 특권을 부여 함으로써 전문가 중심주의를 강화해온다는 비판을 받아 왔다(Shogan, 1998). 이러한 맥락에서 Skrtic(1995)는 특수체육 전문가로서 자신들의 전문적 지식에 대한 권력을 강화하는 과정이 결국 전문가들을 자신들이 가장 객관적 이며 장애 당사자의 최적 이익을 보장할 수 있는 사람이 라는 인식을 고착시켜왔다고 비판했다. 비슷한 맥락에서

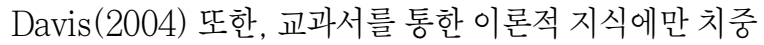

하여 특수체육 실천영역에서의 규범을 획득함으로써 전 문가적 자격을 갖추었다고 여겨지는 사람들에 대해서 장 애에 빌붙어 먹고사는 사람들이라며 혹독하게 비판하였 다. 그러나, 장애학의 선구자인 Shakespeare(2006)는 전문가들의 식견과 장애인의 삶에 대한 개입은 장애인 자 조 모임에 중요한 통찰과 유익을 제공할 수 있다는 점에 서 전문가의 존재를 부정하지는 않았다. 특수체육에서 그 동안 도외시 되었던 전문가적 실천으로서 전문가 개인의 윤리적 관념에 대한 해체와 비평 그리고 반성은 그동안 비판받아온 전문가 중심주의를 극복하는데, 많은 도움을 줄 수 있을 것이다(Skrtic, 1995).

전문가 중심 대한 비판 속에서 등장한 전문가에 대한 두 번째 관점은 장애 당사자를 전문가로 동등하게 인정해 주어야 한다는 주장이다. 특수체육 지도현장에서 장애인 은 특수체육지도자의 무심한 행동의 결과나 사려 깊은 행 동의 결여로 장애를 경험하고 있지만, 장애 전문가로 간 주하지는 않아 왔다. 이러한 맥락에서 장애 관련 단체에 서는 장애인 또한 장애 전문가로서 동등한 지위를 가질 수 있다고 요구해왔다(Bredahl, 2007; Wendell, 1996).

장애 당사자를 전문가로서 바라보아야 한다는 관점은 장애를 사회적 차별과 편견의 관점에서 설명하는 사회구 성주의를 기반으로 한 사회적 모델의 등장으로 대두되었 다. 이렇듯 장애이론의 변화는 누가 장애에 있어 전문가 이며, 전문가로서 중요한 결정을 하는 데 있어 무엇이 옳 고 그른 것인가에 대한 논의를 촉발한다.

그러나, 사회적 모델에 기반을 둔 장애 이해 모델이 전 적으로 옳은 것인가에 대해서는 비판적으로 검토해보아야 한다. 만약, 사회적 모델을 지지하는 입장에서 과거 장애 를 이해하는 주요 패러다임으로 군림하며 건강하고 정상 적인 몸을 표준으로 상정했던 장애의 의료적 모델을 장애 인 당사자의 관점에서 악한 것으로 바라본다면, 장애인이 현재 겪고 있는 고통의 영향과 삶의 피로에 대해서 침묵하 게 되는 것은 아닌가 자문해볼 필요가 있다는 것이다.

장애의 사회적 모델이 사회적 맥락에서 생성되는 장 애에 초점을 둠으로써 장애인이 겪는 불평등을 조명하였 다는 데 의의가 있지만, 앞서 언급한 장애인들이 개별적 으로 경험하는 만성적 고통과 삶의 질 저하와 같은 구체 적인 특성을 무시하게 된다는 한계가 있다. 따라서, 장 애를 이분법적으로 나누어 특수체육 지도현장의 전문가 
를 오롯이 특수체육지도자로만 생각하거나 장애 당사자 로만 이해하는 것을 경계해야 한다.

동 종목을 중도시각장애인의 특성에 맞게 변형하여 이 들에게 적합한 신체활동 유형으로 재구성하는 것이 필요 하다. 다양한 운동 종목을 변형함으로써 중도시각장애인 이 참여할 수 있는 신체활동 유형의 폭을 확장하여 이들 이 기존에 즐기던 유형의 신체활동을 지속할 수 있다면, 이들에게 유능 감과 자율성을 보장하여 지속적인 신체활 동 참여를 유도함으로써 사회적 고립을 최소화함과 동시 에 정신적 신체적 건강의 효과적인 관리를 도모할 수 있 을 것이다.

\section{요약 및 결론}

최근 장애인체육 분야에 많은 윤리적 이슈가 언론을 통해 보도되고 있음에도 특수체육학 분야에는 실천영역 에서 발생할 수 있는 윤리적 이슈에 관한 윤리학적 고찰 을 시도한 연구를 찾아보기 어려운 실정이다. 이에 본 연 구자는 윤리학의 기저를 이루는 윤리이론인 공리주의, 의 무주의, 생명 의료 윤리인 원리주의, 덕윤리, 돌봄의 윤 리, 장애 윤리의 이론을 고찰하고, 각 이론이 특수체육 실 천영역에 제시할 수 있는 함의가 무엇인지 탐색하고자 하 였다. 연구 결과를 정리하면 다음과 같다. 첫째, 우리의 상식적인 도덕 감에서는 받아들이기 어렵겠지만, 윤리를 공리를 위한 수단적 관점에서 접근하는 공리주의적 관점 에서는 통합체육수업에서 발생할 수 있는 장애 학생의 소 외 현상이나 장애 학생의 체벌과 같이 다수의 수업참여를 위해 소수를 희생하는 지도방법은 윤리적으로 정당화될 수 있었다. 따라서, 공리주의를 보완하기 위해 의무주의 나 원리주의가 함께 적용되어야 함을 논하였다.

둘째, 의무주의 윤리는 특수학교 체육이나 장애인 엘 리트 체육 현장에서 지도자들에게 윤리원칙 준수의 중요 함을 일깨워주는 동시에 도덕적 상대주의를 극복하여 도 덕적 자율성과 책임의식을 길러줄 수 있다는 장점이 있을 수 있지만, '순수이성'을 바탕으로 '선의지'를 실현하기 어 려워 보이는 발달 장애 학생과 선수들이 스스로 보편화 가능한 도덕법칙을 설정할 수 있는지에 대해서는 의문이 들게 한다. 인간 존엄의 근거를 이성에 기반을 두고 있는
의무주의 윤리는 필연적으로 이성 능력에 제한이 있어 보 이는 사람들의 존엄성을 보장하기 위한 윤리이론으로 사 용되기에는 한계가 있어 보인다.

셋째, 윤리원칙의 최소전략을 제시하는 원리주의는 특 수체육 지도자가 할 수 있는 행동의 최소한도의 윤리적 한계점을 제시해줄 수 있다는 데 의의가 있다. 그러나, 원 리주의에서 제시하고 있는 '자율성'이라는 가치가 과연 특 수체육 실천의 목적이 될 수 있는가에 대해서는 '상호의 존성'이라는 관점에서 비판적 검토가 필요해 보인다.

넷째, 의무주의와 원리주의가 제시하는 추상적인 윤리 원칙의 한계에 대한 대안으로 제시된 덕윤리는 특수체육 지도자의 개별적 인성에 함양의 중요성을 강조한다는 데 의의가 있었지만, 개인의 덕이 타인에게도 과연 선으로 이어질 수 있을지는 비판적 검토가 필요함을 언급하였다.

다섯째, 돌봄은 항상 옳다고 전제하는 돌봄의 윤리가 특수체육실천의 윤리적 근거로 활용될 경우, 명백하게 존 재하는 장애 당사자의 선택과 자율성이 침해될 수 있음을 언급하였다. 따라서, 돌봄의 윤리를 특수체육학 실천의 윤리적 근거로 사용하고자 할 때는 장애 당사자의 필요와 요구가 무엇인지 세심하게 살필 필요가 있다.

여섯째, 장애 윤리적 관점에서 바라보면 특수체육 실 천과정에서 특수체육지도자뿐만 아니라 장애 당사자 또 한 '장애'에 관해서는 전문가일 수 있음을 고찰해볼 수 있 었다. 그러나, 동시에 장애이론에 대한 이분법적 사고에 갇혀 특수체육지도자나 장애 당사자 한쪽을 일방적인 전 문가로 이해하는 것에 대해서는 경계해야 할 것을 언급하 였다.

마지막으로 이상에서 언급한 윤리이론 중 생명 의료 윤리인 '원리주의'와 ‘돌봄의 윤리'는 단기간에 이루어지 는 의료적 모델에 의해 구성된 운동프로그램 실천을 안내 하는 주요한 윤리이론으로 활용될 수 있음을 고찰하였다. 반면, 장애 당사자의 삶의 질을 높이기 위해 개인의 선택 을 증진하고 개인의 자율성보다는 상호의존의 가치를 추 구하고자 한다면 장애에 대한 지식이나 경험이 아니라 장 애 당사자가 경험하는 '장애' 그 자체에 더 큰 의의를 두는 덕윤리가 특수체육실천의 적절한 윤리적 틀로 자리할 수 있음을 고찰할 수 있었다. 


\section{참고문헌}

Allmark, P. (1995). Can there be an ethics of care? E-Journal of Journal of Medical Ethics, 21, 19-24.

Austin, W. (2007). The ethics of everyday practice. E-Journal of Advances in Nursing Science, 30, 81-88.

Back, S. Y., \& Park, B. D. (2016). The Study on the Ethical Sensitivity and the Consciousness of the Vocational Ethics for the Prospective Adapted Sport Instructors. Korean Journal of Adapted Physical Activity, 24(4), 23-33.

Beauchamp, T. L., \& Childress, J. F. (2001). Principles of biomedical ethics (5th ed.). New York: Oxford University Press.

Beauchamp, T.L. (1995). Principlism and its alleged competitors. Kennedy Institute of Ethics Journal, 5, 181-198.

Begley, A.M. (2006). Facilitating the development of moral insight in practice: Teaching ethics and teaching virtue. Nursing Philosophy, 7, 257-265.

Benner, P. (1997). Adialogue between virtue ethics and care ethics. Theoretical Medicine, 18, 47 - 61.

Bennett, C. (2010). What is this thing called ethics? New York, NY: Routledge.

Bentham, J. (1890). Utilitarianism. Progressive Publishing Company.

Bentham, J. (1988). The principles of morals and legislation. 1789. Amherst, NY: Prometheus Books, 25.

Bredahl, A. (2007). Participation of people with disabilities in adapted physical activity research. E-Journal of Sobama Journal, 12, 74-79.

Burkhardt, M., \& Nathaniel, A. (2013). Ethics and issues in contemporary nursing. Nelson Education.

Byun, S. Y. (2012). A Study on the Present Situations of Subject "Philosophie/Ethik" in Germany. Korean Elementary Moral Education Society. 38, 267-286.

Cardol, M., De Jong, B.A., \& Ward, C.D. (2002). On autonomy and participation in rehabilitation. Disability and Rehabilitation, 24, 970 - 974.

Carlson, L. (2010). Who's the expert? Rethinking authority in the face of intellectual disability. Journal of Intellectual Disability Research, 54, 58 - 65.

Chang, Y. K., \& Lee, J. T. (2014). Study of Physical Education as a Separated Subject in Elementary School Lower Grades. The Journal of Korea Elementary Education, 25(4), 129-147.
Clegg, J. (2000). Beyond ethical individualism. Journal of Intellectual Disability Research, 44, 1 - 11.

Clouser, K.D., \& Gert, B. (1990). A critique of principlism. The Journal of Medicine and Philosophy, 15, 219-236.

Cote, J.E., \& Levine, C.G. (2002). Identity formation, agency, and culture. London: Lawrence Erlbaum.

Davis, K. (2004). Crafting good clients. In J. Swain, S. French, C. Barnes, \& C. Thomas(Eds.), Disabling barriers: Enabling environments (2nd ed., pp. 203 - 205). Thousand Oaks, CA: Sage.

DePauw, K. (2009). Ethics, professional expectations, and graduate education: Advancing research in kinesiology. E-Journal of Quest, 61, 52-58.

Goodwin, D. L., \& Rossow-Kimball, B. (2012). Thinking ethically about professional practice in adapted physical activity. Adapted Physical Activity Quarterly, 29(4), 295-309.

Goodwin, D.L. (2008). Self-regulated dependency: Ethical reflections on interdependence and help in adapted physical activity. Sport, Ethics and Philosophy, 2, 172-184.

Goodwin, D.L., \& Watkinson, J. (2000). Inclusive physical education from the perspective of students with physical disabilities. E-Journal of Adapted Physical Activity Quarterly, 17, 144-160.

Hanford, L. (1993). Ethics and disability. E-Journal of British Journal of Nursing, 2, 979-982.

Jeremy, B. (1789). An introduction to the principles of morals and legislation. London: $\mathrm{T}$.

Jo, G. R. (2018). A Study on Child Abuse of Children with Disabilities in Adapted Physical Education Field. an unpublished doctoral thesis, Seoul National University, Seoul.

Jo, G. R., \& Kang, Y. S. (2019). Exploring the Ethical Conflicts of Adapted Physical Activity Instructors. Korean Journal of Adapted Physical Activity, 27(2), 139-153.

JoongAang Ilbo(2016. 8. 22). 장애아동 머리 때리고 폭언한 특수 체육 교사 ‘집유’. http://news.joins.com/article/20484340

Kim, H. S., \& Kim D. K. (2010). Justifications for observance of sports rules. Philosophy of Movement : Journal of Korean Philosophic Society for Sport and Dance, 18(1), 45-64.

Kim, J. H. (2015). Sports ethics. Seoul: Rainbowbooks.

Kim, M. S. (2002). Development of a Multidimensional Group Norm Scale for Primary School Sport Teams. Korean Journal of Sport Psychology, 13(1), 1-13.

Kim, S. K (2015). A Stydy on Utilitarianism and Deontology 
surrounding Doping. Philosophy of Movement : Journal of Korean Philosophic Society for Sport and Dance. 23(1), 19-41.

Korea Paralympic Committee(2012). Report on the status of violence in sports of people with disability.

Lee, J. T. (2016). A Study on the Approaches of Ethics to Physical Education. The Korean Journal of Elementary Physical Education, 22(1), 49-62.

Lee, W. S., \& Kim, J. T. (2012). Analysis of Factors Affecting Ethical Sensibility of Adapted Physical Education Majors. Korean Journal of Adapted Physical Activity, 20(1), 1-13.

Lee, Y. H. (2012). Code of Ethics and Ethics Education as Means to Resolve Ethical Issues in Adapted Physical Activity in Korea. Korean Journal of Adapted Physical Activity, 22(2), 119-128.

Macklin, R. (1998). Ethical relativism in a multicultural society. Kennedy Institute of Ethics Journal, 8, 1-22.

Mill, J. S. (2016). Utilitarianism. In Seven masterpieces of philosophy (pp. 337-383). Routledge.

Noddings, N. (1984). Caring: A feminine approach to ethics and moral education. Berkeley, CA: University of California Press.

Oberle, K., \& Raffin Bouchal, S. (2009). Ethics in Canadian nursing practice: Navigating the journey. Toronto, ON: Prentice Hall.

Oh, H. T., \& Kim, Y. K. (2008). The Critique of Utilitarianism Theory Concerning Sports Events. Philosophy of Movement : Journal of Korean Philosophic Society for Sport and Dance. 16(3), 69-81.

Oh, J. S., \& Kim, S. Y. (2015). A Case Study on Judgments in Women"s Apparatus Gymnastics. Journal of Coaching Development, 17(3), 167-178.

Park, C. K. (2014). Our ethics. Seoul: Seogwangsa.

Park, S. J. (2014). Theoretical Foundations on Sport Ethics. Philosophy of Movement : Journal of Korean Philosophic
Society for Sport and Dance. 22(3), 77-97.

Park, S. J. (2016). An Analysis of Match-Fixing from the Ethical Point of View. The Korean Journal of Physical Education, 55(4), 13-22

Reid, G. (2000). Future directions of inquiry in adapted physical activity. E-Journal of Quest, 52, 369-381.

Seo, K. H., \& Hwang, J. H. (2014). Ethical Consideration on Intentional Foul in Sport Competitions. Philosophy of Movement : Journal of Korean Philosophic Society for Sport and Dance. 22(4), 79-93.

Shakespeare, T. (2006). Disability rights and wrongs. London: Routledge.

Shogan, D. (1998). The social construction of disability: The impact of statistics and technology, E-Journal of Adapted Physical Activity Quarterly, 15, 269-277.

Skrtic, T. (Ed.). (1995). Disability \& democracy: Reconstructing [special] education for postmodernity. New York, NY: Teachers College Press.

Sports Chosun(2014. 9. 13). ‘체벌로 발달장애아 뇌진탕' 전 대 안학교 교사 입건. http://sports.chosun.com/news/utype.htm? id=201409130000000000007889\&ServiceDate=20140913

Wendell, S. (1996). The rejected body: Feminist philosophical perspectives on disability. London: Routledge.

Yonhap News Agency(2017. 5. 31). 장애 어린이 의자에 묶어 수 업 ‘논란’...학부모 ‘분통’. http://www.yonhapnews.co.kr/bull etin/2017/05/31/0200000000AKR20170531140400060.

Yoo, J. A., Seo, J. Y., Jang, Y. K., Kim, K. C., \& Kwon, M. J. (2007). AResearch on the Explanation of Physical Education Process in Elementary and Middle School. Korea Institute for Curriculum and Evaluation.

Yoo, S. J. (2016). Criticism and Communitarian Reinterpretation of Beauchamp and Childress Four Principles. The Korean Bioethics Association, 17(2), 17-36. 


\title{
특수체육실천영역에 관한 윤리학적 고찰
}

\author{
조가람 \\ 나사렛대학교, 조교수
}

특수체육학 분야에는 실천영역에서 발생하는 윤리이슈에 관한 비판적 탐구를 시도한 연구가 매우 부족한 실정이다. 실천영역에서 윤리적 고찰이 필요한 이유는 특수체육지도자들이 자신의 의도와는 무관하게 지도현 장에서 장애학생과 같은 타인의 삶에 부정적인 영향을 미칠 수 있기 때문이다. 〔목적) 따라서 본 연구의 목적 은 특수체육실천 영역에서 나타날 수 있는 윤리이슈에 대한 윤리이론을 적용하고 시사점을 고찰하는 것이다. 〔방법〕 본 연구자는 공리주의, 의무주의, 원칙주의, 덕윤리, 돌봄의 윤리이론을 통해 특수체육실천 영역에서 무엇이 옳고, 그른 것이지, 또는 무엇이 좋고 나쁜 것인지에 관한 비판적 고찰을 시도하였다.〔결과〕 연구 결 과로 윤리이론을 고찰하고 각 이론이 특수체육실천에 제시할 수 있는 기여와 한계점을 논의하였다.

주요어: 윤리, 특수체육, 공리주의, 의무주의, 원칙주의, 덕윤리, 돌봄의 윤리 